\title{
Cardiovascular and metabolic responses to tap water ingestion in young humans: does the water temperature matter?
}

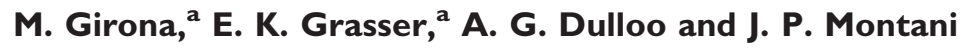 \\ Department of Medicine, Division of Physiology, Laboratory of Integrative Cardiovascular and Metabolic Physiology, University of \\ Fribourg, Fribourg, Switzerland
}

Correspondence: E. K. Grasser, Division of Physiology, Department of Medicine, University of Fribourg, Chemin du Musée 5, 1700 Fribourg, Switzerland. E-mail: erikkonrad.grasser@unifr.ch

aM. Girona and E. K. Grasser contributed equally to this work.

\begin{abstract}
Aim: Drinking water induces short-term cardiovascular and metabolic changes. These effects are considered to be triggered by gastric distension and osmotic factors, but little is known about the influence of water temperature.

Methods: We determined, in a randomized crossover study, the acute cardiovascular and metabolic responses to $500 \mathrm{~mL}$ of tap water at $3{ }^{\circ} \mathrm{C}$ (cold), $22^{\circ} \mathrm{C}$ (room) and $37^{\circ} \mathrm{C}$ (body) in 12 young humans to ascertain an effect of water temperature. We measured continuous beat-to-beat haemodynamics, skin blood flux with laser-Doppler flowmetry and resting energy expenditure by indirect calorimetry starting with a 30-min baseline followed by a 4-min drink period and a subsequent 90-min post-drink observation.
\end{abstract}

Results: Ingestion of cold- and room-tempered water led to decreased heart rate $(P<0.01)$ and double product $(P<0.01)$, and increased stroke volume $(P<0.05)$; these effects were not observed with body-tempered water. Drinking cold- and room-, but not body-tempered water, led to increased high frequency power of heart rate variability $(P<0.05)$ and baroreflex sensitivity $(P<0.05)$. Cold- and room-tempered water increased energy expenditure over 90 min by $2.9 \%(P<0.05)$ and $2.3 \%$ (ns), respectively, accompanied by a diminished skin blood flux $(P<0.01)$, thereby suggesting that both small increases in heat production together with decreased heat loss contribute to warming up the ingested water to intra-abdominal temperature levels.

Conclusions: Overall, ingestion of cold- and room-, but not body-tempered water reduced the workload to the heart through a reduction in heart rate and double product which could be mediated by an augmented cardiac vagal tone.

Keywords baroreflex, haemodynamics, vagal, variability.
Despite its daily usage, the haemodynamic, autonomic and metabolic responses to water ingestion in humans are not well understood. In patients suffering from severe autonomic failure, drinking water increased substantially blood pressure (BP) (Jordan et al. 1999, 2000, Cariga \& Mathias 2001) accompanied by a rise of plasma noradrenaline (Jordan et al. 2000). However, the pressure response due to ingestion of similar amounts of water is not seen in young and healthy subjects (Joannidès et al. 1999, Jordan et al. 2000, Scott et al. 2001, Brown et al. 2005) despite an augmented muscle sympathetic nerve activity and a rise in 
plasma noradrenaline levels (Scott et al. 2001). This could be related to an increase in cardiac vagal control, which counteracts the changes in the sympathetic tone (Routledge et al. 2002), in response to osmotic factors. Indeed, ingestion of distilled water, but not the same amount of a physiological saline solution, increased sympathetic and parasympathetic activity in healthy subjects (Brown et al. 2005), suggesting that the water osmolality impacts on the cardiovascular system.

Although humans prefer to drink water or a flavoured beverage at a temperature below usual room temperatures (Burdon et al. 2012), studies addressing the role of water temperature on cardiovascular and metabolic changes are scarce. There are only a few reports where the effects of water temperature on resting energy expenditure (EE) were investigated in healthy humans (Boschmann et al. 2003, Brown et al. 2006), but to date, a comprehensive study on the haemodynamic and metabolic impact of water temperature is lacking. Previously, thermosensitive vagal afferent nerve fibres have been identified in the gastrointestinal tract in animals (Gupta et al. 1979, El Ouazzani \& Mei 1982) as well as in humans (Villanova et al. 1997). Therefore, we hypothesized that ingestion of water at different temperatures influences human cardiac vagal tone. A secondary aim was to investigate the effect of the water temperature on metabolic parameters $\left(\mathrm{VO}_{2}\right)$ and skin blood flow in the context of the hypothesis that cold-tempered water would influence cutaneous vasoconstriction and body heat storage.

To test these hypotheses, we compared, on a beatto-beat basis in a randomized crossover design, the cardiovascular and autonomic variables in response to cold $\left(3^{\circ} \mathrm{C}\right)-$, room $\left(22^{\circ} \mathrm{C}\right)$ - and body-tempered $\left(37^{\circ} \mathrm{C}\right)$ tap water, and evaluated additionally their potentially differential impacts on skin blood flux and resting EE.

\section{Methods}

\section{Subjects}

Twelve healthy young adults (eight men, four women), aged 20-26 (mean $22.7 \pm 0.5$ ) year, were recruited from local students and their friends. The mean height of the participants was $173 \pm 3 \mathrm{~cm}$, body weight was $65 \pm 4 \mathrm{~kg}$, and their body mass index was $21.5 \pm 0.6 \mathrm{~kg} \mathrm{~m}^{2}$. None of the subjects had any diseases or were taking any medication affecting cardiovascular or autonomic regulation. All participants were studied in the morning after an overnight (12-h) fast and they were requested to avoid alcohol or caffeine for at least $24 \mathrm{~h}$ prior to the test. Written informed consent was obtained from each test subject. Our study is in conformation with the Good Publishing Practice in Physiology for publications in Acta Physiology Oxford introduced by Persson (2013).

\section{Experimental protocol}

All experiments took place in a quiet, temperaturecontrolled $\left(22 \pm 1{ }^{\circ} \mathrm{C}\right)$ laboratory and started between 08:00 and 09:00. Every subject attended three separate experimental sessions (each session separated by at least 2 days) according to a randomized crossover study. Randomization was performed using a random sequence generator (http://www.random izer.org/form.htm) where the sessions order was determined for 12 test subjects before the study started ( 1 = COLD, 2 = ROOM, 3 = BODY). We determined our sample size based on a study (Routledge et al. 2002) where the cardiac vagal response to water ingestion was investigated in healthy humans. This study observed an increase in RR interval from $893 \mathrm{~ms}$ (standard deviation $73 \mathrm{~ms}$ ) at baseline to $1001 \mathrm{~ms} 20 \mathrm{~min}$ after ingesting $500 \mathrm{~mL}$ room-tempered tap water. We chose a type I error $(\alpha)$ of 0.05 and a desired power $(1-\beta)$ of 1.00 at which suggests that for such an investigation of repeated measures (on the same subject), a total number of 12 subjects would be required. On arrival at the laboratory, subjects were asked to empty their bladders if necessary and to sit in a comfortable armchair. Subjects clothing consisted of a T-shirt, trousers and shoes. The equipment for cardiovascular monitoring, skin blood flow measurement and indirect calorimetry was then attached, and the upper body was covered with a light blanket. Following a period for cardiovascular and metabolic stability (20-30 min), a baseline recording was then made for $30 \mathrm{~min}$. Then, the test subjects ingested over $4 \mathrm{~min}$, either $500 \mathrm{~mL}$ of cold $\left(3^{\circ} \mathrm{C}\right)$-, room $\left(22^{\circ} \mathrm{C}\right)$-, or body-tempered $\left(37^{\circ} \mathrm{C}\right)$ tap water, and cardiovascular, skin blood flux and metabolic recordings were monitored for $90 \mathrm{~min}$. Subjects drank the water using their left hand but otherwise not changing the position. During the drinking period, the oscillometric and continuous BP measurement ceased and immediately restarted after finishing the drink. Throughout the procedures, subjects were permitted to watch documentaries.

\section{Measurements}

Haemodynamics. A Task Force Monitor (TFM) (CNSystems, Medizintechnik, Graz, Austria) was used to perform cardiovascular recordings, and data were sampled at a rate of $1000 \mathrm{~Hz}$ (Brown et al. 2005). Continuous BP was monitored using the 
Penaz principle from either the index or middle finger (automatically finger switch every $30 \mathrm{~min}$ ) of the right hand and was calibrated to oscillometric brachial BP measurements on the contralateral arm. Oscillometric blood pressure measurements were derived during baseline and the post-drink period about every $5 \mathrm{~min}$ $(5.4 \pm 0.1 \mathrm{~min})$. The right hand with the continuous BP cuff rested on a ductile pillow which was positioned at heart level on a height adjustable table. Impedance cardiography measurements (Grasser et al. 2009), in which the changes in thoracic impedance are converted to reflect changes in thoracic fluid content/volume over time, were performed based on the original Kubicek (Kubicek et al. 1970) approach but using an improved estimate of thoracic volume (Fortin et al. 2006), which allows calculation of cardiac stroke volume (SV). ECG/impedance electrodes were positioned together with upper arm and finger BP cuffs. Electrode strips were placed at the neck and thoracic regions, the latter specifically at the midclavicular at the xiphoid process level (CNSystems standard electrode kits).

Heart rate variability and baroreflex sensitivity. High frequency (HF: $0.17-0.40 \mathrm{~Hz}$ ) power components of RR intervals (HF_RRI) were evaluated and given in absolute values $\left(\mathrm{ms}^{2}\right)$. Keeping in mind the limitations (Parati et al. 2006), we used changes in the HF range of heart rate variability to assess parasympathetic activity because HF_RRI is primarily mediated by parasympathetic nerve modulation (Pagani et al. 1997, Stauss 2003). Powers of HF_RRI were analysed after natural logarithmic transformation. Baroreflex sensitivity (BRS) was determined from spontaneous fluctuations in BP and cardiac interval using the sequence technique (Bertinieri et al. 1985).

Skin blood flux (SkBF). Microcirculatory skin blood perfusion was assessed continuously and non-invasively on the dorsum of the right hand between the thumb and the index finger by laser-Doppler flowmetry (Stern 1975, Nilsson et al. 1980) (Perimed, Periflux System PF5001, Järfälla, Sweden). Laser-Doppler flowmetry signals were given in arbitrary units (AU), and the method reflects changes in SkBF accurately (Johnson et al. 1984). The within-subject variability for the 30-min baseline period between the drinks was $23 \pm 4 \%$. Before the attachment of the sensor, the dedicated area was cleaned with an alcohol swap and the residence time was set for $1 \mathrm{~min}$. Thereafter, the sensor was attached.

Indirect calorimetry. Respiratory gas exchange was measured by indirect calorimetry using an open-circuit ventilated hood system (Deltatrac monitor, Datex,
Helsinki, Finland) as described previously (Brown et al. 2006). Respiratory exchange ratio (RER) was derived from the rates of oxygen consumption and carbon dioxide production and EE using the Weir equation (Weir 1949).

Data and statistical analysis. Values of cardiac interval, systolic blood pressure (SBP), diastolic blood pressure (DBP), SV, SkBF, EE and RER were averaged every $15 \mathrm{~min}$ during the baseline period and the 90min post-drink period. Cardiac output (CO) was derived as the product of SV and heart rate (HR), where HR was calculated from the appropriate cardiac interval. Total peripheral resistance (TPR) was calculated as mean blood pressure (MBP) divided by CO, where MBP was calculated as the result of DBP $+1 / 3$ (SBP-DBP). Double (rate pressure) product (DP) was calculated as HR - SBP and provides valuable information for the oxygen consumption of the myocardium (Van Vliet \& Montani 1999).

All values are reported as means \pm SE. Statistical analysis was performed by two-way ANOvA for repeated measures with time and treatment (drink type: cold, room and body) as within-subject factors using statistical software (STATISTIX version 8.0; Analytical Software, St. Paul, MN, USA). Where significant differences were found, the effects of each drink over time were analysed by comparing values at each time point over the post-drink period with the basal values recorded during the $30 \mathrm{~min}$ immediately before drinking. Nonparametric statistic tests were used for BRS, HF_RRI, SkBF and RER after testing for normal distribution using the D'Agostino and Pearson omnibus normality test. Repeated-measures ANOVA with Dunnett's multiple comparison post hoc testing or the Friedman test with Dunns post hoc testing was used to test for changes over time from baseline level (left panels on Figs 1-4). Repeated-measures ANOva with Newman-Keuls post hoc testing or the Friedman test with Dunns post hoc testing was used to compare mean changes averaged over 45 and 90 min between drink conditions (right panels on Figs 1-4). A paired $t$-test or a Wilcoxon matched pair test was used to compare mean changes (45 and $90 \mathrm{~min}$ ) of each drink with baseline levels. All reported $P$ values are twosided. For all tests, significance was set at $P \leq 0.05$.

\section{Results}

\section{Cardiovascular responses}

Resting baseline values of SBP, DBP, HR, DP, SV, CO and TPR were not significantly different (Table 1 ). None of the subjects reported any discomfort after the drink was ingested. 

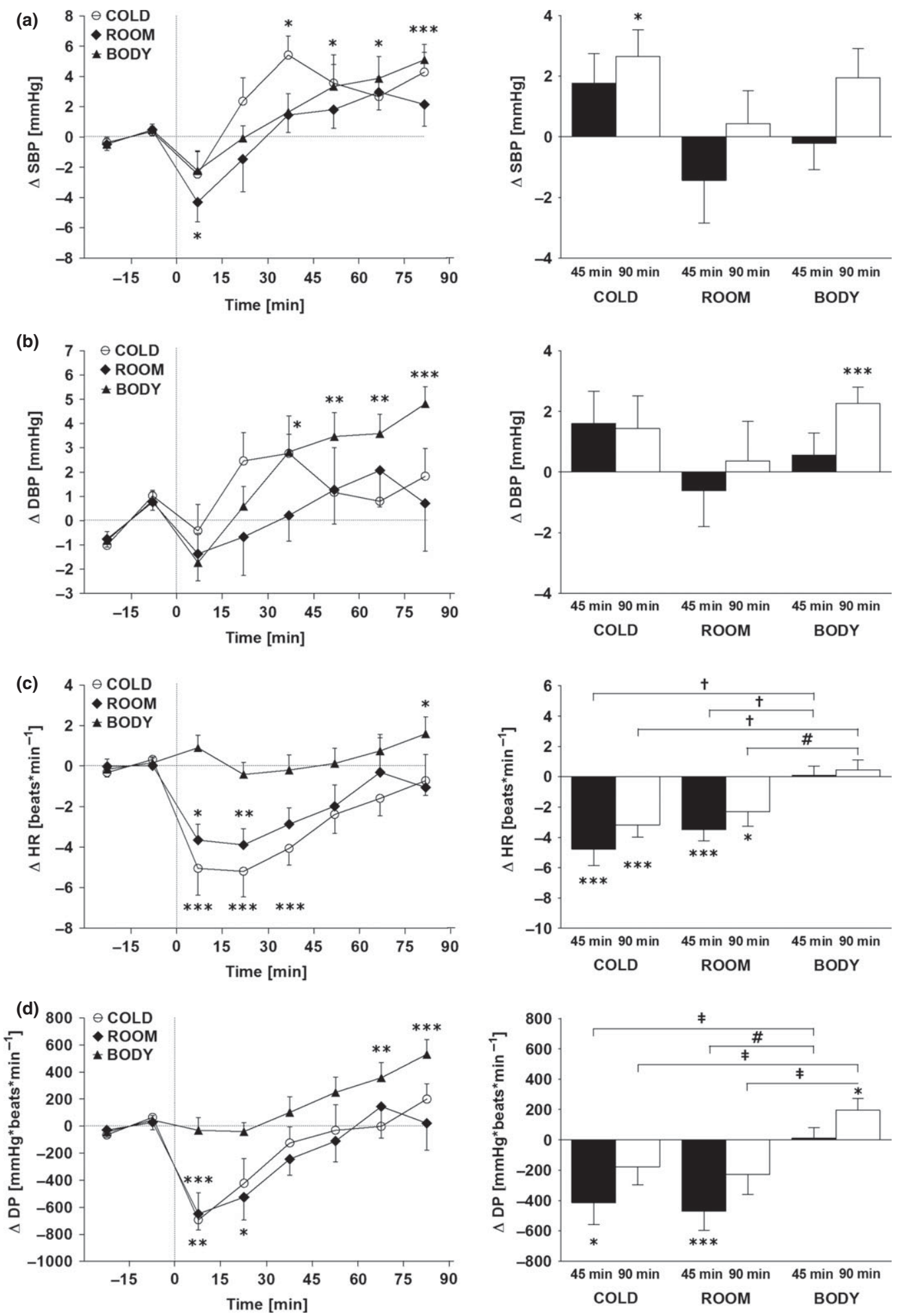

Figure I (a-d) Left panel: Time course of the changes in continuous systolic blood pressure (SBP) (a), continuous diastolic blood pressure (DBP) (b), heart rate (HR) (c) and rate pressure double product (DP) (d). Right panel: Mean responses averaged over 45 and 90 min relative to baseline values and presented as a delta (i.e. average over 45 and 90-min post-drink period, respectively, minus the average over the 30 -min baseline period) after drinking cold water $\left(3^{\circ} \mathrm{C}\right)$, room water $\left(22^{\circ} \mathrm{C}\right)$ or bodytempered water $\left(37^{\circ} \mathrm{C}\right)$. Time 0 indicates 4 min after ingestion each of the drinks. ${ }^{*} P<0.05, * * P<0.01$ and $* * P<0.005$ statistically significant differences over time from baseline values (left and right panel). ${ }^{\ddagger} P<0.05,{ }^{\#} P<0.01$ and ${ }^{\dagger} P<0.005$, statistically significant differences between responses to the drinks (right panel). All values are reported as means $\pm \mathrm{SE}$. 

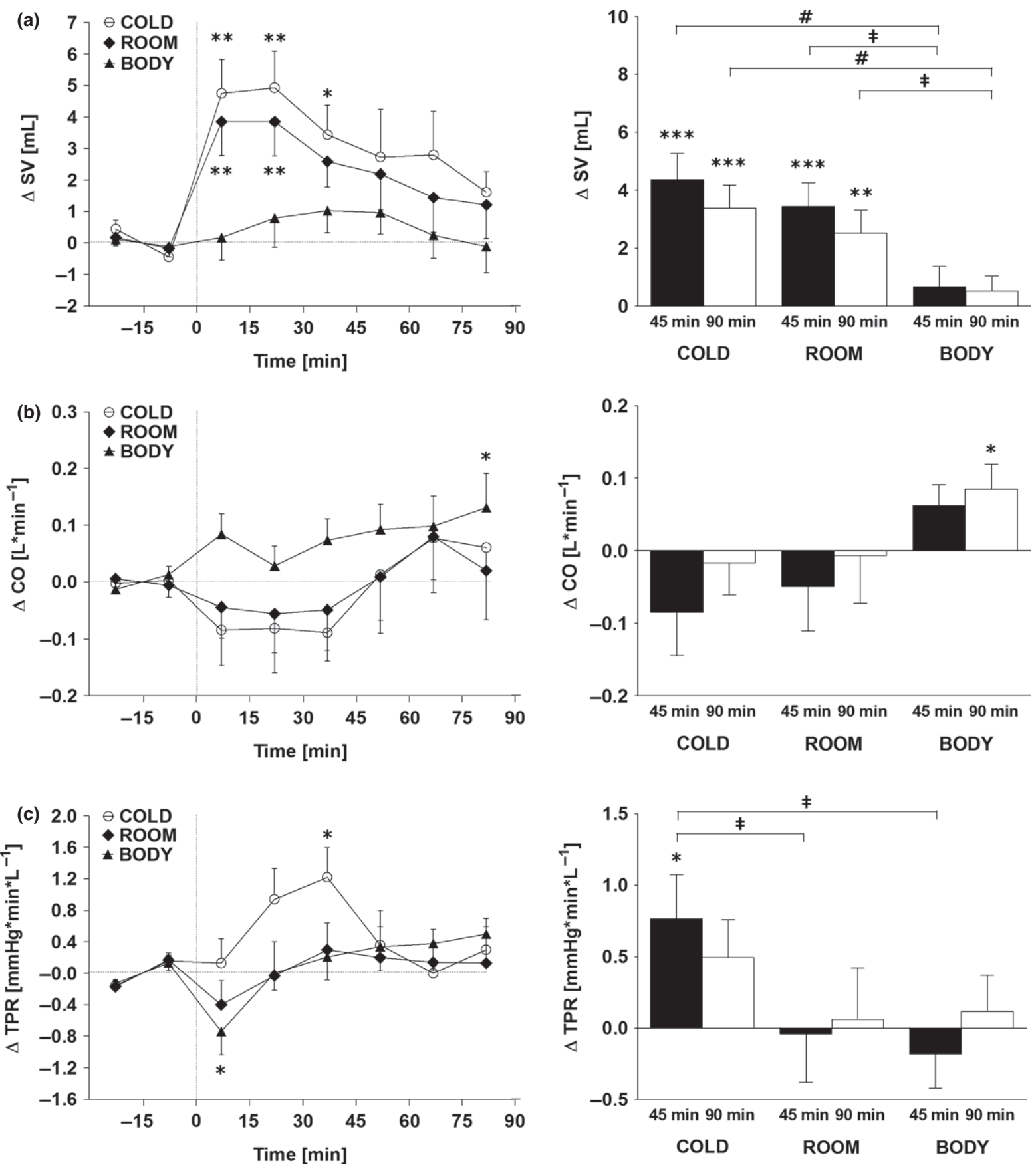

Figure 2 (a-c) Left panel: Time course of the changes in stroke volume (SV) (a), cardiac output (CO) (b) and total peripheral resistance (TPR) (c). Right panel: Mean responses averaged over 45 and 90 min relative to baseline values and presented as a delta (i.e. average over 45- and 90-min post-drink period, respectively, minus the average over the 30-min baseline period) after drinking cold water $\left(3{ }^{\circ} \mathrm{C}\right)$, room water $\left(22^{\circ} \mathrm{C}\right)$ or body-tempered water $\left(37^{\circ} \mathrm{C}\right)$. Time 0 indicates 4 min after ingestion each of the drinks. $* P<0.05, * * P<0.01$ and $* * P<0.005$ statistically significant differences over time from baseline values (left and right panel). ${ }^{\star} P<0.05$ and ${ }^{\#} P<0.01$, statistically significant differences between responses to the drinks (right panel). All values are reported as means $\pm \mathrm{SE}$.

The time course and changes of 45- and 90-min averages related to baseline values of cardiovascular parameters are shown in Figure 1 for SBP, DBP, HR and DP. Ingestion of water at different temperatures resulted in significant interaction effects (time $\times$ drink $)$ for DBP $(P<0.05)$ and $\mathrm{HR}$ $(P<0.05)$. SBP and DBP initially tended to drop below baseline levels after each drink. Cold water 

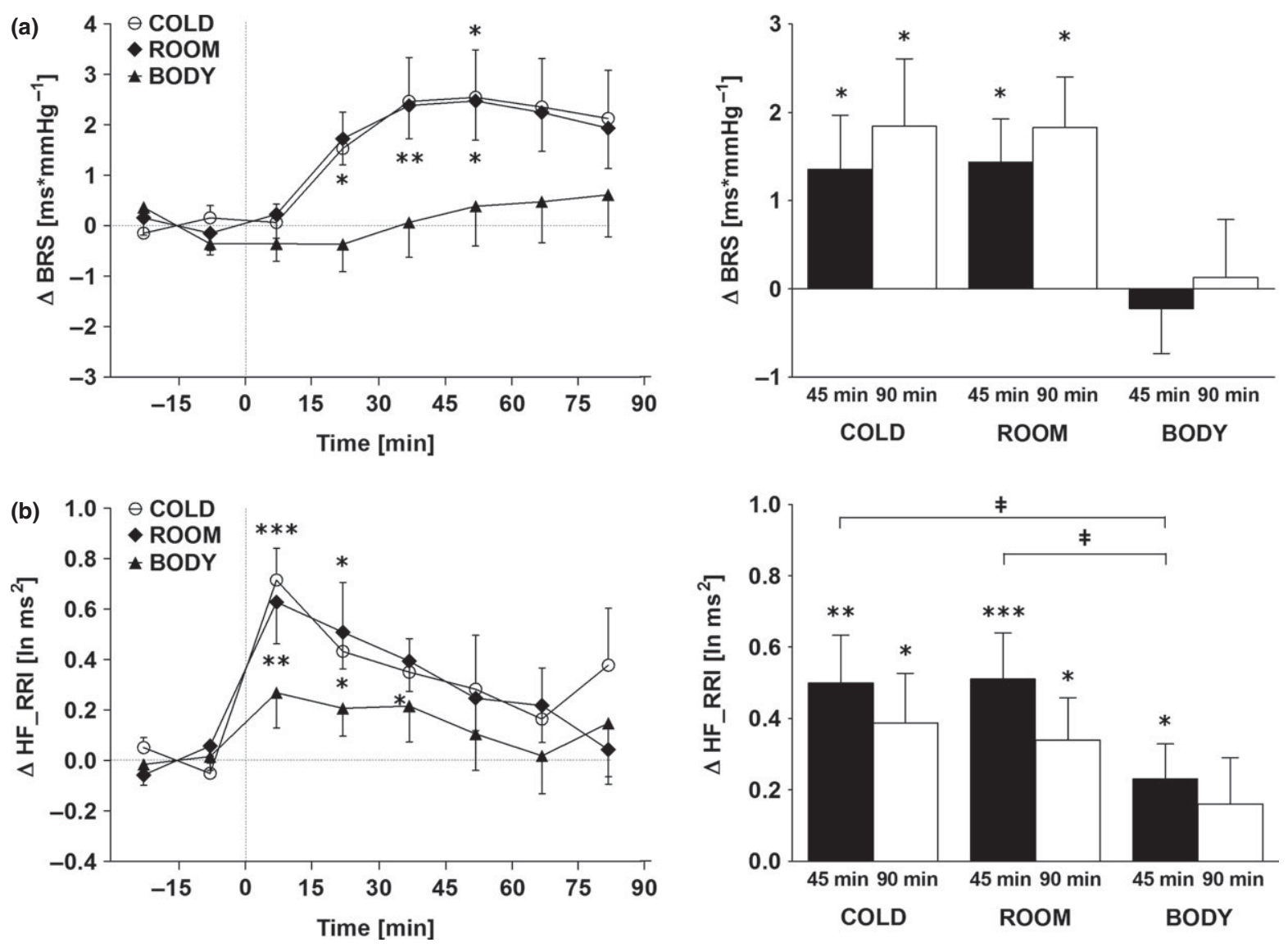

Figure 3 (a) and (b) Left panel: Time course of the changes in baroreflex sensitivity (BRS) (a) and high frequency power of RR interval (HF_RRI) (b). Right panel: Mean responses averaged over 45 and 90 min relative to baseline values and presented as a delta (i.e. average over 45- and 90-min post-drink period, respectively, minus the average over the 30-min baseline period) after drinking cold water $\left(3{ }^{\circ} \mathrm{C}\right)$, room water $\left(22^{\circ} \mathrm{C}\right)$ or body-tempered water $\left(37^{\circ} \mathrm{C}\right)$. Time 0 indicates 4 min after ingestion each of the drinks. $* P<0.05, * * P<0.01$ and $* * * P<0.005$, statistically significant differences over time from baseline values (left and right panel). ${ }^{\ddagger} P<0.05$, statistically significant differences between responses to the drinks (right panel). All values are reported as means $\pm \mathrm{SE}$.

raised SBP levels to an early peak at about $45 \mathrm{~min}$ $(+5.4 \mathrm{mmHg})$, whilst body-tempered water showed a more gradual increase peaking at $90 \mathrm{~min}$ for DBP and SBP $(+4.8 \mathrm{mmHg}$ and $+5.1 \mathrm{mmHg})$. Compared with baseline levels, body-tempered water increased DBP $(+2.3 \mathrm{mmHg})$ over a 90-min average, whilst cold water raised SBP $(+2.6 \mathrm{mmHg})$. Cold- and room-tempered water drinking resulted in an immediate drop in HR below baseline levels, with the largest dip occurring at around $30 \mathrm{~min}$ (cold: -5.2 beats $\mathrm{min}^{-1}$; room: -3.9 beats $\min ^{-1}$ ) and with a gradual increase towards baseline values afterwards. Body-tempered water did not influence HR. The average 45- and 90min decreases in heart rate for cold (45 $\mathrm{min}:-4.8$ beats $\min ^{-1}$; $90 \mathrm{~min}$ : -3.2 beats $\left.\min ^{-1}\right)$ - and for room-tempered water (45 $\mathrm{min}:-3.5$ beats $\mathrm{min}^{-1}$; 90 min: -2.3 beats $\min ^{-1}$ ) were significantly different compared with body-tempered water. Cold- and room-tempered water significantly decreased DP in the first 15 min compared with baseline values, by $-692 \mathrm{mmHg}$ beats $\mathrm{min}^{-1}$ and by $-648 \mathrm{mmHg}$ beats $\min ^{-1}$ respectively; this was followed by a gradual increase towards baseline levels. Ingestion of bodytempered water showed a stable DP for the first 45 min with the onset of a gradual increase towards a late peak $\left(+532 \mathrm{mmHg}\right.$ beats $\left.\mathrm{min}^{-1}\right)$ at $90 \mathrm{~min}$. The average 45- and 90-min responses in DP for bodytempered water were significantly different compared with cold-tempered water ( $45 \mathrm{~min}:+11$ vs. $-413 \mathrm{~mm}$ $\mathrm{Hg}$ beats $\min ^{-1}$; $90 \mathrm{~min}$ : +195 vs. $-179 \mathrm{mmHg}$ beats $\mathrm{min}^{-1}$ ) and room-tempered water (45 $\mathrm{min}:+11$ vs. $\quad-472 \mathrm{mmHg}$ beats $\min ^{-1}$; $90 \mathrm{~min}: \quad+195$ vs. $-227 \mathrm{mmHg}$ beats $\mathrm{min}^{-1}$ ).

The time course and changes of 45- and 90-min averages relative to baseline values are shown for SV, $\mathrm{CO}$ and TPR in Figure 2. Cold-tempered water tended to elevate TPR above baseline levels with a peak $\left(+1.2 \mathrm{mmHg} \operatorname{min~} \mathrm{L}^{-1}\right)$ at $45 \mathrm{~min}$, whilst 

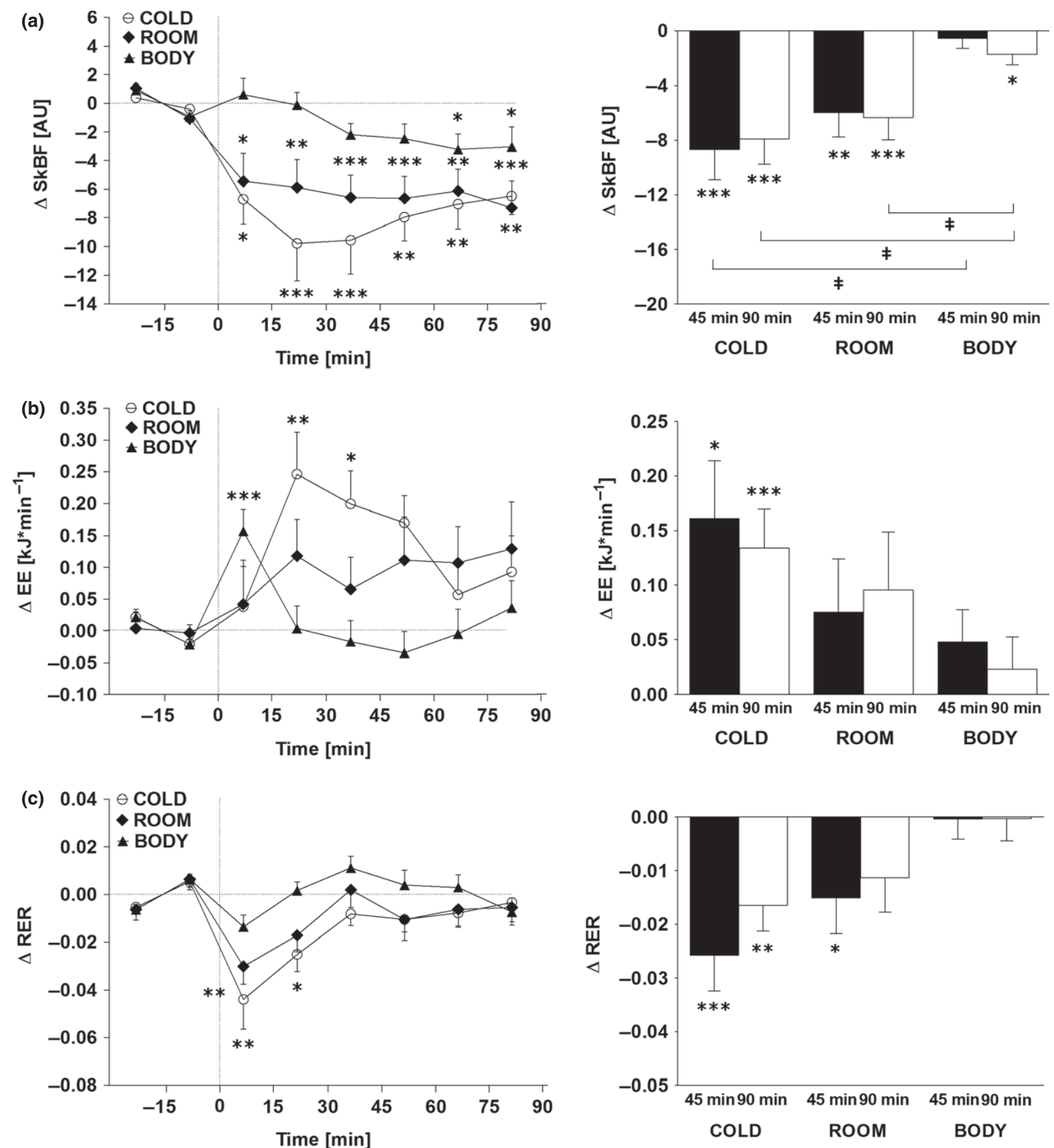

Figure $4(\mathrm{a}-\mathrm{c})$ Left panel: Time course of the changes in skin blood flux (SkBF) (a), resting energy expenditure (EE) (b) and respiratory exchange ratio (RER) (c). Right panel: Mean responses averaged over 45 and 90 min relative to baseline values and presented as a delta (i.e. average over 45 - and 90 -min post-drink period, respectively, minus the average over the 30 -min baseline period) after drinking cold water $\left(3^{\circ} \mathrm{C}\right)$, room water $\left(22^{\circ} \mathrm{C}\right)$ or body-tempered water $\left(37^{\circ} \mathrm{C}\right)$. Time 0 indicates 4 min after ingestion each of the drinks. $* P<0.05, * * P<0.01$ and $* * P<0.005$, statistically significant differences over time from baseline values (left and right panel). ${ }^{\ddagger} P<0.05$, statistically significant differences between responses to the drinks (right panel). All values are reported as means \pm SE.

room-tempered water did not impact on TPR. Bodytempered water initially dropped TPR by $-0.7 \mathrm{mmHg} \operatorname{min~} \mathrm{L}^{-1}$ with a subsequent gradual return towards baseline levels. The average 45-min increase in TPR for cold-tempered water was significantly different compared with room-tempered water $\left(+0.77\right.$ vs. $\left.-0.04 \mathrm{mmHg} \operatorname{min~} \mathrm{L}^{-1}\right)$ and to body-tempered water $(+0.77$ vs. $-0.18 \mathrm{mmHg}$ min $\left.\mathrm{L}^{-1}\right)$. Drinking cold- and room-tempered water immediately raised SV over baseline levels peaking at 
Table I Baseline data recorded $30 \mathrm{~min}$ prior ingesting each of the drinks (data are presented as means $\pm \mathrm{SE}$ )

\begin{tabular}{|c|c|c|c|}
\hline Drink temperature & Cold $\left[3^{\circ} \mathrm{C}\right]$ & Room $\left[22^{\circ} \mathrm{C}\right]$ & Body $\left[37^{\circ} \mathrm{C}\right]$ \\
\hline Systolic blood pressure, $\mathrm{mmHg}$ & $114 \pm 2$ & $114 \pm 2$ & $114 \pm 2$ \\
\hline Diastolic blood pressure, $\mathrm{mmHg}$ & $72 \pm 1$ & $71 \pm 1$ & $73 \pm 1$ \\
\hline Heart rate, beats $\min ^{-1}$ & $63 \pm 2$ & $61 \pm 2$ & $64 \pm 2$ \\
\hline Stroke volume, $\mathrm{mL}$ & $75 \pm 4$ & $75 \pm 3$ & $74 \pm 4$ \\
\hline Double product, $\mathrm{mmHg}$ beat $\min ^{-1}$ & $7112 \pm 187$ & $6941 \pm 210$ & $7257 \pm 245$ \\
\hline Cardiac output, $\mathrm{L} \min ^{-1}$ & $4.60 \pm 0.12$ & $4.54 \pm 0.12$ & $4.61 \pm 0.18$ \\
\hline Total peripheral resistance, $\mathrm{mmHg} \mathrm{L}^{-1} \mathrm{~min}$ & $18.8 \pm 0.5$ & $18.9 \pm 0.7$ & $19.1 \pm 0.9$ \\
\hline Baroreflex sensitivity, $\mathrm{ms} \mathrm{mmHg}^{-1}$ & $22.5 \pm 2.3$ & $22.7 \pm 2.7$ & $18.4 \pm 2.1$ \\
\hline Resting energy expenditure, $\mathrm{kJ} \min ^{-1}$ & $4.49 \pm 0.25$ & $4.40 \pm 0.23$ & $4.51 \pm 0.28$ \\
\hline Resting oxygen consumption, $\mathrm{mL} \min ^{-1}$ & $225 \pm 13$ & $221 \pm 11$ & $226 \pm 14$ \\
\hline Respiratory exchange ratio & $0.82 \pm 0.01$ & $0.82 \pm 0.01$ & $0.83 \pm 0.01$ \\
\hline Skin blood flux, arbitrary units & $27.7 \pm 3.2$ & $27.0 \pm 2.8$ & $26.7 \pm 2.3$ \\
\hline
\end{tabular}

$30 \mathrm{~min}$ (cold: $+4.9 \mathrm{~mL}$ and room: $+3.9 \mathrm{~mL}$ ), whilst body-tempered water did not influence SV. Averaging over 45 and 90 min post-drink periods, SV showed that cold $(45 \mathrm{~min}:+4.4$ vs. $0.7 \mathrm{~mL} ; 90 \mathrm{~min}:+3.4$ vs. $+0.5 \mathrm{~mL}$ )- and room (45 min: +3.4 vs. $0.7 \mathrm{~mL}$; $90 \mathrm{~min}:+2.5$ vs. $+0.5 \mathrm{~mL}$ )-tempered water differed significantly from body-tempered water. Although not significantly different across the drinks when compared as the post-drink 90-min averages, body-tempered water, but not cold- or room-tempered water, increased $\mathrm{CO}$ relative to baseline $\left(+0.09 \mathrm{~L} \mathrm{~min}^{-1}\right)$ over $90 \mathrm{~min}$.

\section{Autonomic responses}

Baseline BRS did not differ between the conditions (Table 1). Time course and changes of 45- and 90min averages to baseline values are shown for BRS and HF_RRI in Figure 3. A significant drink vs. time effect could be found for BRS $(P<0.01)$. Ingestion of cold- and room-tempered water resulted in a parallel time course for BRS starting to rise over baseline levels between 30 and $45 \mathrm{~min}$, peaking after $60 \mathrm{~min}$ (cold: $+2.5 \mathrm{~ms} \mathrm{mmHg}^{-1}$; room: $+2.5 \mathrm{~ms} \mathrm{mmHg}^{-1}$ ) and plateauing afterwards, whilst body-tempered water did not impact on BRS. Cold- and roomtempered water increased significantly BRS over 45 and $90 \mathrm{~min}$ post-drink (45 min: $+1.4 \mathrm{~ms} \mathrm{mmHg}^{-1}$ and $+1.4 \mathrm{~ms} \mathrm{mmHg}^{-1}$; $90 \mathrm{~min}$ : $+1.8 \mathrm{~ms} \mathrm{mmHg}^{-1}$ and $+1.8 \mathrm{~ms} \mathrm{mmHg}^{-1}$ ) compared with baseline values. Cold- and room- but not body-tempered water increased HF_RRI after ingestion peaking at $15 \mathrm{~min}$ (cold: $+0.72 \mathrm{ln} \mathrm{ms}{ }^{2}$; room: $+0.63 \mathrm{ln} \mathrm{ms}^{2}$ ) with a subsequent gradual decrease towards baseline values. Data averaged over 45 and 90 min post-drink showed an elevated HF_RRI with cold- (45 min: $0.50 \mathrm{ln} \mathrm{ms}^{2}$; 90 min: $+0.39 \ln \mathrm{ms}^{2}$ ), room- (45 min: $0.51 \mathrm{ln} \mathrm{ms}^{2}$; $90 \mathrm{~min}:+0.34 \mathrm{ln} \mathrm{ms}^{2}$ ) and to a lesser extent bodytempered water (45 min: $0.23 \mathrm{ln} \mathrm{ms}^{2}$ ) compared with baseline levels. The average 45-min response in HF_RRI for body-tempered water was significantly different compared with cold- and room-tempered water.

\section{Metabolic changes and skin blood flux}

Baseline resting EE, baseline resting oxygen consumption, RER and SkBF did not differ between the drinks (Table 1). Time course and changes of 45- and 90min averages relative to baseline values are shown for SkBF, EE and RER in Figure 4. A significant drink vs. time effect was found for SkBF $(P<0.05)$ and $\mathrm{EE}$ $(P<0.01)$. All drink conditions led to diminished SkBF over time with cold water showing the largest drop compared with baseline levels at $30 \mathrm{~min}$ (-9.8 AU). Room-tempered water gradually decreased SkBF from the very start showing a minimum at 90 min $(-7.3 \mathrm{AU})$. Ingestion of body-tempered water did not change SkBF for the first $30 \mathrm{~min}$, followed by a slow decrease below baseline values. The 90-min average for SkBF showed a significant difference between both cold- and room-tempered water when compared to body-tempered water, with cold water showing the largest drop (-7.9 AU) compared with baseline levels. The 45-min average for SkBF during cold water ingestion was significantly lower (-8.7 AU) compared with body-tempered water (-0.6 AU). Referring to EE, the time course for coldand room-tempered water showed, after an initial stable period, an increase in EE, particularly with cold water, peaking at $30 \min \left(0.25 \mathrm{~kJ} \mathrm{~min}^{-1}\right)$ with a subsequent gradual decrease. Drinking body-tempered water increased EE immediately after ingestion with a peak $\left(+0.16 \mathrm{~kJ} \mathrm{~min}^{-1}\right)$ at $15 \mathrm{~min}$ with a rapid return to baseline values.

Considering the controversy on water-induced increases in resting energy expenditure in response to osmolality and temperature (Boschmann et al. 2003, 
Table 2 Effect of drinking water at different temperatures on resting energy expenditure in young humans (EE, resting energy expenditure; SkBF, skin blood flux). All values are reported as means $\pm \mathrm{SE}$

\begin{tabular}{|c|c|c|c|}
\hline & Cold $\left[3{ }^{\circ} \mathrm{C}\right]$ & Room $\left[22^{\circ} \mathrm{C}\right]$ & Body $\left[37^{\circ} \mathrm{C}\right]$ \\
\hline $\mathrm{EE}$, baseline, $\mathrm{kJ} \min ^{-1}$ & $4.49 \pm 0.25$ & $4.40 \pm 0.23$ & $4.51 \pm 0.28$ \\
\hline $\mathrm{EE}, 60 \min ^{*}, \mathrm{~kJ} \min ^{-1}$ & $4.65 \pm 0.27^{\ddagger}(+3.6 \%)$ & $4.49 \pm 0.24(+2.0 \%)$ & $4.53 \pm 0.28(+0.4 \%)$ \\
\hline $\mathrm{EE}, 90 \min ^{\dagger}, \mathrm{kJ} \min ^{-1}$ & $4.62 \pm 0.26^{\ddagger}(+2.9 \%)$ & $4.50 \pm 0.25(+2.3 \%)$ & $4.53 \pm 0.28(+0.4 \%)$ \\
\hline SkBF, baseline, AU & $27.7 \pm 3.2$ & $27.0 \pm 2.8$ & $26.7 \pm 2.3$ \\
\hline $\mathrm{SkBF}, 60 \min ^{*}, \mathrm{AU}$ & $19.2 \pm 1.4^{*}(-30.7 \%)$ & $20.9 \pm 2.3^{\ddagger}(-22.6 \%)$ & $25.7 \pm 2.8(-3.7 \%)$ \\
\hline SkBF, $90 \min ^{\dagger}, \mathrm{AU}$ & $19.8 \pm 1.6^{*}(-28.5 \%)$ & $20.7 \pm 2.2^{\ddagger}(-23.3 \%)$ & $25.0 \pm 2.7^{\S}(-6.4 \%)$ \\
\hline
\end{tabular}

*Average over 60 min post-drink (percentage changes are given in parentheses).

${ }^{\dagger}$ Average over 90 min post-drink (percentage changes are given in parentheses).

${ }^{*}$ Refers to $P<0.005$ and ${ }^{\S}$ refers to $P<0.05$, compared with baseline values using either one-way anova with Newman-Keuls (EE) or the Friedman test with Dunns post hoc testing (SkBF).

Brown et al. 2006), we provided with the data presented in Table 2, a direct comparison to the results of our previous study (Brown et al. 2006). Comparing values at baseline with a 60- and 90-min average resulted in a significant increase in EE after ingestion of cold- but not room- or body-tempered water (Table 2). RER showed only a transient decrease after ingestion of cold- and room-tempered water with an afterwards gradual return towards baseline values (Fig. 4). Comparing values at baseline with a 60- and 90-min average resulted in a decreased SkBF after ingestion of cold $(-30.7$ and $-28.5 \%)$ - and roomtempered $(-22.6$ and $-23.3 \%)$ water. Body-tempered water decreased SkBF 90 min after ingestion (-6.4\%) but not at $60 \mathrm{~min}$ (Table 2).

\section{Comparison between oscillometric and continuous BP measurements}

Because of potential effects of peripheral vasoconstriction induced by drinking cold water on continuous BP measurements (finger cuff measurements), we analysed SBP and DBP in two distinct sets and compared BP responses between cold- and body-tempered water. One set concentrated on the period with the lowest SkBF, suggesting the most prominent cutaneous vasoconstriction, between 15 and $30 \mathrm{~min}$ post-drink (Fig. 5a and b), and the second set encompassed the whole 90-min post-drink period (Fig. 5c and d). Our results showed an overall difference of -2.4 $1.6 \mathrm{mmHg}(P=0.15)$ for $\mathrm{SBP}$ and $-1.3 \pm 1.3 \mathrm{mmHg}$ $(P=0.50)$ for DBP between oscillometric and continuous BP measurements when body- and cold-tempered water were compared with each other between 15 and 30 min post-drink. These differences were attenuated (SBP: $\quad-0.4 \pm 0.6 \mathrm{mmHg}, \quad P=0.33 ; \quad$ DBP: $-0.5 \pm 0.7 \mathrm{mmHg}, P=0.50)$ when the observation period was extended over the whole 90 min study duration.

\section{Discussion}

The present study demonstrates differential cardiovascular and metabolic responses to the temperature of drinking water in young and healthy adults. We observed an increase in cardiac vagal tone and a corresponding decrease in HR with cold- and room-tempered water, but not with body-tempered water. This, in combination with a dropping DP, diminished substantially the workload to the heart for approx. 45 min after ingestion. Furthermore, cold- and roomtempered water produced peripheral skin vasoconstriction (measured with a laser-Doppler flux approach) and increased EE, suggesting that processes that prevent heat loss and increase heat production both play a role in the warming up of cold- and room-tempered water to intra-abdominal temperature levels.

We found an immediate and substantial depression of HR after ingestion of cold- and room-tempered water within $30 \mathrm{~min}$ post-ingestion. This drop was even more pronounced with cold water and was not seen with body-tempered water, which suggests a graded physiological HR response to the water temperature. An explanation for these results can be derived from our data on heart rate variability and baroreflex sensitivity indicating increased cardiac vagal tone with cold- and room- but not body-tempered water. Indeed, a fall in HR - associated with increased HF_RRI powers and increased BRS - is considered as enhanced cardiac vagal tone. This indicates that ingestion of water below a certain intra-abdominal temperature level raises the cardiac vagal tone which results in a declining HR. Our data with coldand room-tempered water are in line with those from a previous study which found that ingestion of $500 \mathrm{~mL}$ tap water (temperature $18{ }^{\circ} \mathrm{C}$ ) resulted in a significant rise in cardiac vagal tone with a corresponding reduction in HR (Routledge et al. 2002). Using a similar amount of distilled water at room 

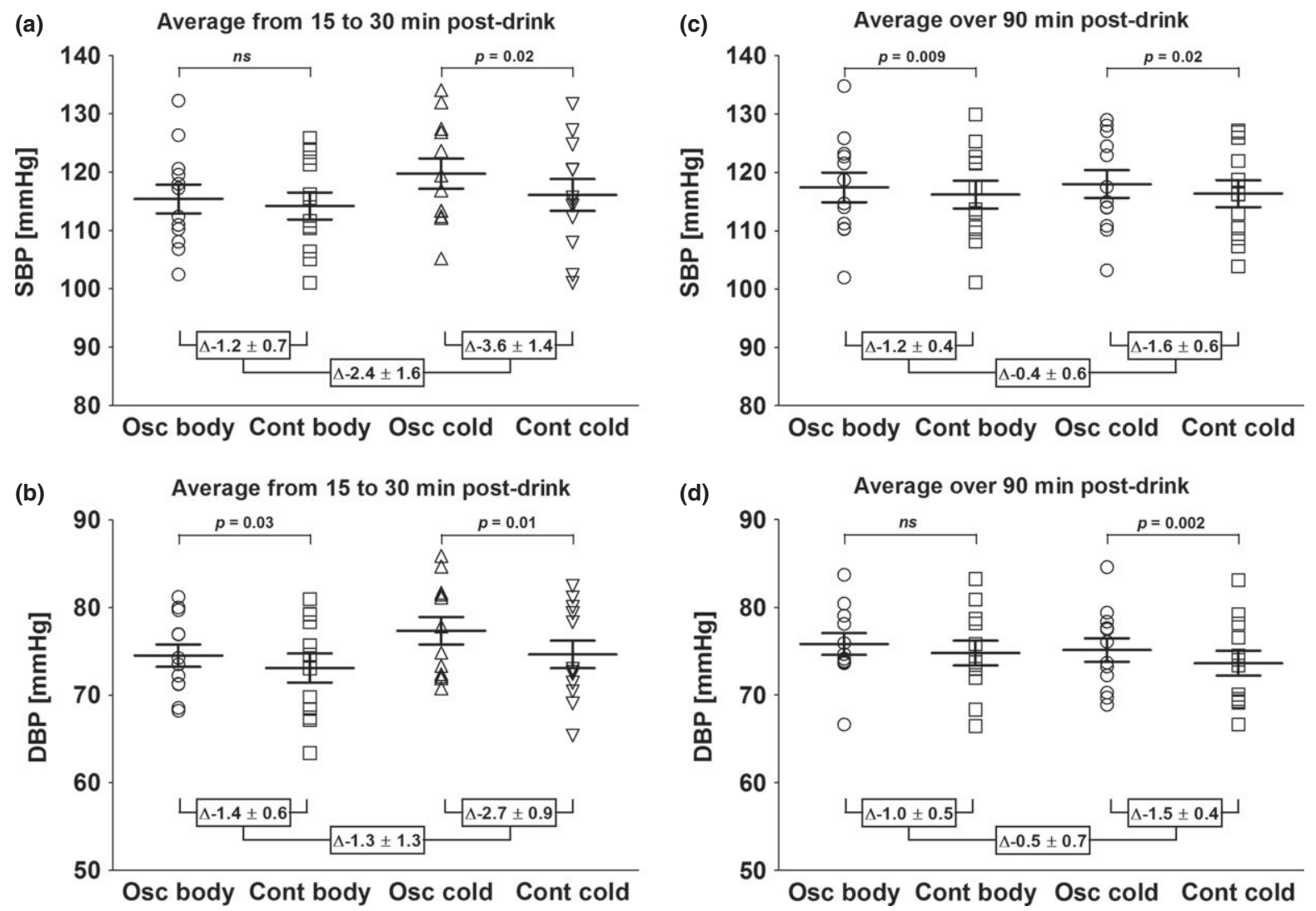

Figure 5 (a) and (b) Scatter plot graph for oscillometric (Osc) or continuous (Cont) systolic blood pressure (SBP) and diastolic blood pressure (DBP) measurements averaged in the period from 15 to 30 min post-drink. (c) and (d) Scatter plot graph for oscillometric (Osc) or continuous (Cont) systolic blood pressure (SBP) to diastolic blood pressure (DBP) measurements averaged over 90 min post-drink. A paired $t$-test was used to compare oscillometric with continuous blood pressure measurements and significance was set at $P<0.05 . \Delta$ refers to the difference in $\mathrm{mmHg}$ between Osc and Cont blood pressure measurements and to the difference between body-tempered (body $=37^{\circ} \mathrm{C}$ ) and cold-tempered $\left(\right.$ cold $=3{ }^{\circ} \mathrm{C}$ ) water. Data are presented as means \pm SE.

temperature $\left(21^{\circ} \mathrm{C}\right)$, previous work from our laboratory (Brown et al. 2005) also found increased HF_RRI powers and BRS, and decreased HR. Besides confirming these findings, the study reported here shows that the water temperature influences the cardiac vagal tone in a graded manner. It is possible that our observed changes relates to an activation of thermosensitive afferent vagal nerve fibres which were found in oesophagus, stomach and duodenum (Gupta et al. 1979, El Ouazzani \& Mei 1982, Villanova et al. 1997). More recent studies revealed underlying transduction mechanisms of cold sensitivity in vagal afferents in cultured vagal sensory neurones in the rat and mouse nodose ganglion (Zhang et al. 2004, Fajardo et al. 2008), in mammalian cell lines (Story et al. 2003) and in a specific cloned menthol receptor from trigeminal sensory neurones (McKemy et al. 2002). It seems plausible that ingestion of water activates distinct gastrointestinal vagal afferent nerve fibres in a temperature-dependent manner and could influence subsequent cardiac vagal tone. Therefore, we provide with our findings new evidence that, beside the known influence of osmolality on autonomic functions (Brown et al. 2005, May \& Jordan 2011), the temperature of the water influences cardiac vagal tone. However, it is not yet clear whether an interaction between temperature and osmolality sensing exists on a molecular basis. On the one hand, TRPA1 and TRPM8 are known to be activated by temperatures below core body temperature $\left(<28^{\circ} \mathrm{C}\right.$ ) (McKemy et al. 2002, Story et al. 2003, Fajardo et al. 2008) and could hence deliver through sensorial vagal neurones temperature-related information to the brainstem (Fajardo et al. 2008). To our knowledge, however, there are no reports that TRPA1 or TRPM8 can sense osmolality. On the other hand, TRPV4 is known to sense and transmit information on both temperature (Güler et al. 2002, Watanabe et al. 2002) and osmolality (Liedtke et al. 2000, Strotmann et al. 2000, Güler et al. 2002, McHugh et al. 2010) and starts to oper- 
ate in HEK293 cells at temperatures between $25^{\circ} \mathrm{C}$ (Watanabe et al. 2002) and $34^{\circ} \mathrm{C}$ (Güler et al. 2002). It is possible that in our test subjects, the ingested cold- and room-tempered water, warming up within a short period of time to intra-abdominal environmental temperature levels, could hence activate TRPV4.

We observed SV to be inversely related to HR, with the largest increase occurring with cold water and a blunted response to body-tempered water. Our data on SV with room-tempered water are also in line with our previous study indicating that ingestion of distilled water $\left(21^{\circ} \mathrm{C}\right)$ at a similar volume resulted in a significant increase in SV up to $30 \mathrm{~min}$ after ingestion (Brown et al. 2005). In our study here, CO did not change in response to cold- or room-tempered water suggesting that the reduction in HR was mainly offset by reciprocal changes in SV.

Ingestion of room-tempered tap water has been shown to increase BP in autonomic failure patients (Jordan et al. 1999, 2000, Cariga \& Mathias 2001), whereas in healthy humans, BP was found unchanged (Joannidès et al. 1999, Jordan et al. 2000, Scott et al. 2001, Brown et al. 2005) in response to either tap- or distilled water consumption at room temperature. In accordance with the latter studies in healthy humans, we were not able to detect an effect of room-tempered water on BP. However, both cold- and body-tempered water tended to increase BP, albeit differently. Indeed, SBP but not DBP increased significantly after ingestion of cold water, whereas body-tempered raised only DBP significantly. Another difference was found in the time course for the BP response where ingestion of cold water showed a biphasic course and body-tempered water resulted in a gradual increase over time. The observed rise in SBP after cold water was accompanied by an increase in TPR and a corresponding decline in SkBF, which indicates peripheral skin vasoconstriction in response to cold water ingestion. On the other hand, body-tempered water increased BP rather through changes in CO than in TPR with little effect on SkBF, which is indicative of different autonomic mechanisms being involved. Further evidence for a different autonomic mechanism can be derived from the calculated DP indicating that body-tempered water resulted in a higher myocardial oxygen demand compared with cold- or room-tempered water. It is of note that our pulse pressure data did not correlate with changes in SV and thus could not account for the change in SBP with cold drink.

To date, we are only aware of one published study where the influence of water ingestion on SkBF was evaluated ( $\mathrm{Lu}$ et al. 2012). This group ( $\mathrm{Lu}$ et al. 2012) found that after ingestion of $500 \mathrm{~mL}$ water at room temperature $\left(21-24^{\circ} \mathrm{C}\right)$, the SkBF immediately dropped and remained below control levels for up to
50 min (by approx. 30\% compared with their control). In agreement with this finding, we found an immediate and substantial decrease in SkBF in response to drinking cold water $(-30.7 \%$ by $60 \mathrm{~min})$ and room-tempered water $(-28.5 \%$ by $60 \mathrm{~min})$ reaching a minimum approx. $45 \mathrm{~min}$ after their respective ingestion. In contrast, this drop in SkBF was not seen with body-tempered water. Interestingly, $\mathrm{Lu}$ et al. (2012) also observed, concomitant with the drop in SkBF, an increase in TPR, particularly for the first $40 \mathrm{~min}$. In our study, the calculated TPR was found to be increased with cold water for the first $40 \mathrm{~min}$ but not with room-tempered water. It is suggested that the difference in the subjects' posture between our study (sitting in an armchair) and the study by $\mathrm{Lu}$ et al. (2012) (lying supine) could be attributed to the observed discrepancy for TPR after ingestion roomtempered water.

Our observed drop in SkBF was accompanied by a rise in $\mathrm{EE}$ in response to drinking cold water: $+2.9 \%$ over $90 \mathrm{~min}(3.6 \%$ over $60 \mathrm{~min})$. These data are consistent with our previous study where ingestion of a similar amount of distilled cold water $\left(3{ }^{\circ} \mathrm{C}\right)$ was found to increase EE by $4.5 \%$ over $60 \mathrm{~min}$ (Brown et al. 2006). Boschmann et al. (2003) have previously reported much larger increases in $\mathrm{EE}(+30 \%)$ in response to drinking $500 \mathrm{~mL}$ of water at room temperature, and that heating water from room- $\left(22^{\circ} \mathrm{C}\right)$ to body temperature $\left(37^{\circ} \mathrm{C}\right)$ reduced the post-drink increase in $\mathrm{EE}$ by $40 \%$. This attenuation in waterinduced thermogenesis was reported to be similar to the calculated amount of energy required to warm the ingested water from room to intra-abdominal levels (approx. $30 \mathrm{~kJ}$ for $500 \mathrm{~mL}$ ) (Boschmann et al. 2003). On the basis of these findings and calculations, it would be expected that ingestion of cold water would further augment thermogenesis and EE. However, we found only a small increase in EE following ingestion of room-tempered water $(+2.3 \%)$, and although drinking cold water produced a greater increase in EE than drinking room-tempered water, this additional increase with cold water was small (from +2.3 to $+2.9 \%$ above the respective baseline values). These increases in EE with tap water in our study here are hence far below the calculated energy cost of warming the ingested water from $22{ }^{\circ} \mathrm{C}$ to $37^{\circ} \mathrm{C}$ or from $3{ }^{\circ} \mathrm{C}$ to $37^{\circ} \mathrm{C}$ and are consistent with the increases in $\mathrm{EE}$ $(<5 \%)$ previously reported from our laboratory in response to drinking room- or cold-tempered distilled water (Brown et al. 2006). To what extent the discrepancy in the magnitude of water-induced thermogenesis between our laboratory and those of Boschmann et al. (2003) may reside in different methodologies in EE assessment (ventilated hood vs. room calorimetry) or in between-laboratory differences in 
constituents of tap water remains to be investigated. However, our results here showing reductions in SkBF following ingestion of both room- and cold-tempered water suggest that prevention of heat loss through local peripheral skin vasoconstriction may be of greater importance than increasing heat production in the warming up of these water loads to intra-abdominal temperature levels. A recent study in nine healthy males using partitional calorimetry in an environment that permits full evaporation (Bain et al. 2012) found body heat storage to be significantly lower after ingestion of hot water $\left(50^{\circ} \mathrm{C}\right)$ compared with cold water $\left(1.5^{\circ} \mathrm{C}\right)$ during moderate exercise. However, they could not observe significant changes in body heat storage between ingestion of water at 37 and $1.5^{\circ} \mathrm{C}$. Likely explanations for this discrepancy could be due to differences pertaining to the methodology and study protocol used in our study and that of Bain et al. (2012). First, we used indirect calorimetry to access resting energy expenditure where Bain et al. (2012) used partitional calorimetry to access heat storage. Second, our experimental design focused on resting conditions to evaluate the influence of water temperature on the cardiac vagal tone, whilst Bain et al. (2012) used a moderate exercise protocol with different environmental conditions to investigate the influence of water temperature on body heat storage.

We do not have a clear explanation for the early and small drop of RER in response to ingestion of cold water and, to a lesser extent, room-tempered water. However, our results are consistent with those of Boschmann et al. (2003) who also reported that ingestion of $500 \mathrm{~mL}$ water in men led to a drop in RER. It could be speculated that sensorial elements in mouth, pharynx and oesophagus led to the decrease in RER via the autonomic nervous system.

One point of concern could be the validity of our continuous BP (finger cuff) measurements under conditions of a potential cutaneous vasoconstriction. To address this question, we compared intermittent ( every $5 \mathrm{~min}$ ) oscillometric and continuous BP measurements (SBP and $\mathrm{DBP}$ ) using a distinct post-drink period (e.g. 15-30 min post-drink) where the drop in SkBF was most prominent in response to cold- compared with body-tempered water. Our results showed a difference of $-2.4 \mathrm{mmHg}$ for SBP and $-1.3 \mathrm{mmHg}$ for DBP between the oscillometric and continuous BP measurement when comparing body-tempered with cold water (Fig. 5a and b). However, comparing these changes over the 90-min post-drink period revealed that the difference between the cold- and body-tempered drink diminished substantially with differences lower than $-1 \mathrm{mmHg}$ (Fig. 5c and d). These findings suggest that our continuous BP measurements tended to be slightly lower than the intermittent oscillometric
BP measurements, which could be partly explained by a change in SkBF, but this would not affect our overall conclusion.

In conclusion, drinking water at different temperatures evoked distinct cardiovascular and metabolic changes in young and healthy humans. Drinking coldand room-tempered water, but not body-tempered water, increased cardiac vagal tone and decreased substantially the workload to the heart. This observation could be of pertinent clinical importance in daily clinical settings where water drinks are offered to patients and warrant further studies addressing the role of water temperature in distinct human pathologies.

Research related to this paper was funded in part by the Swiss National Science Foundation (Project 3200B0-122554 to JPM).

\section{Conflict of interest}

The study authors declare no conflict interest.

\section{References}

Bain, A.R., Lesperance, N.C. \& Jay, O. 2012. Body heat storage during physical activity is lower with hot fluid ingestion under conditions that permit full evaporation. Acta Physiol (Oxf) 206, 98-108.

Bertinieri, G., di Rienzo, M., Cavallazzi, A., Ferrari, A.U., Pedotti, A. \& Mancia, G. 1985. A new approach to analysis of the arterial baroreflex. J Hypertens Suppl 3, 79-81.

Boschmann, M., Steiniger, J., Hille, U., Tank, J., Frauke, A., Sharma, A.M., Klaus, S., Luft, F.C. \& Jordan, J. 2003. Water-induced thermogenesis. J Clin Endocrinol Metab 88, 6015-6019.

Brown, C.M., Barberini, L., Dulloo, A.G. \& Montani, J.P. 2005. Cardiovascular responses to water drinking: does osmolality play a role? Am J Physiol 289, R1687-R1692.

Brown, C.M., Dulloo, A.G. \& Montani, J.P. 2006. Waterinduced thermogenesis reconsidered: the effects of osmolality and water temperature on energy expenditure after drinking. J Clin Endocrinol Metab 91, 3598-3602.

Burdon, C.A., Johnson, N.A., Chapman, P.G. \& O'Connor, H.T. 2012. Influence of beverage temperature on palatability and fluid ingestion during endurance exercise: a systematic review. Int J Sport Nutr Exerc Metab 22, 199-211.

Cariga, P. \& Mathias, C.J. 2001. Haemodynamics of the pressor effect of oral water in human sympathetic denervation due to autonomic failure. Clin Sci 101, 313-319.

El Ouazzani, T. \& Mei, N. 1982. Electrophysiologic properties and role of the vagal thermoreceptors of lower esophagus and stomach of cat. Gastroenterology 83, 995-1001.

Fajardo, O., Meseguer, V., Belmonte, C. \& Viana, F. 2008. TRPA1 channels mediate cold temperature sensing in mammalian vagal sensory neurons: pharmalogical and genetic evidence. J Neurosci 28, 7863-7875.

Fortin, J., Habenbacher, W., Heller, A., Hacker, A., Grüllenberger, R., Innerhofer, J., Passath, H., Wagner, C., Haitchi, 
G., Flotzinger, D., Pacher, R. \& Wach, P. 2006. Non-invasive beat-to-beat cardiac output monitoring by an improved method of transthoracic bioimpedance measurement. Comp Biol Med 36, 1185-1203.

Grasser, E.K., Goswami, N. \& Hinghofer-Szalkay, H. 2009. Presyncopal cardiac contractility and autonomic activity in young healthy humans. Physiol Res 58, 817-826.

Güler, A.D., Lee, H., Iida, T., Shimizu, I., Tominaga, M. \& Caterina, M. 2002. Heat-evoked activation of the ion channel, TRPV4. J Biol Chem 277, 6408-6414.

Gupta, B.N., Nier, K. \& Hensel, H. 1979. Cold-sensitive afferents from the abdomen. Pflugers Arch 380, 203-204.

Joannidès, R., Moore, N., de la Gueronnière, V. \& Thuillez, C. 1999. Effect of water on arteries. Lancet 354, 516.

Johnson, J.M., Taylor, W.F., Shepherd, A.P. \& Park, M.K. 1984. Laser-doppler measurement of skin blood flow: comparison with plethysmography. J Appl Physiol 56, 798-803.

Jordan, J., Shannon, J.R., Grogan, E., Biaggioni, I. \& Robertson, D. 1999. A potent pressor response elicited by drinking water. Lancet 353, 723.

Jordan, J., Shannon, J.R., Black, B.K., Ali, Y., Farley, M., Costa, F., Diedrich, A., Robertson, R.M., Biaggioni, I. \& Robertson, D. 2000. The pressor response to water drinking in humans - a sympathetic reflex? Circulation 101, 504-509.

Kubicek, W.G., Patterson, R.P. \& Witsoe, D.A. 1970. Impedance cardiography as a non-invasive method of monitoring cardiac function and other parameters of the cardiovascular system. Ann NY Acad Sci 170, 724-732.

Liedtke, W., Choe, Y., Marti-Renom, M.A., Bell, A.M., Denis, C.S., Sali, A., Hudspeth, A.J., Friedman, J.M. \& Heller, S. 2000. Vanilloid receptor-related osmotically activated channel (VR-OAC), a candidate vertebrate osmoreceptor. Cell 103, 525-535.

Lu, C.C., Li, M.H., Lin, T.C., Chen, T.L., Chen, R.M., Tung, C.S., Tseng, C.J. \& Ho, S.T. 2012. Water ingestion reduces skin blood flow through sympathetic vasoconstriction. Clin Auton Res 22, 63-69.

May, M. \& Jordan, J. 2011. The osmopressor response to water drinking. Am J Physiol 300, R40-R46.

McHugh, J., Keller, N.R., Appalsamy, M., Thomas, S.A., Raj, S.R., Diedrich, A., Biaggoni, I., Jordan, J. \& Robertson, D. 2010. Portal osmopressor mechanism linked to transient receptor potential vanilloid 4 and blood pressure control. Hypertension 55, 1438-1443.

McKemy, D.D., Neuhausser, W.M. \& Julius, D. 2002. Identification of a cold receptor reveals a general role for TRP channels in thermosensation. Nature 416, 52-58.

Nilsson, G.E., Tenland, T. \& Oberg, P.A. 1980. Evaluation of a laser doppler flowmeter for measurement of tissue blood flow. IEEE Trans Biomed Eng 27, 597-604.
Pagani, M., Montano, N., Porta, A., Malliani, A., Abboud, F.M., Birkett, C. \& Somers, V.K. 1997. Relationship between spectral components of cardiovascular variabilities and direct measures of muscle sympathetic nerve activity in humans. Circulation 95, 1441-1448.

Parati, G., Mancia, G., Di Rienzo, M., Castiglioni, P., Taylor, J.A. \& Studinger, P. 2006. Point:Counterpoint: Cardiovascular variability is/is not an index of autonomic control of circulation. J Appl Physiol 101, 676-682.

Persson, P.B. 2013. Good publication practice in physiology 2013: revised author guidelines for Acta Physiologica. Acta Physiol (Oxf) 209, 250-253.

Routledge, H.C., Chowdhary, S., Coote, J.H. \& Townend, J.N. 2002. Cardiac vagal response to water ingestion in normal human subjects. Clin Sci 103, 157-162.

Scott, E.M., Greenwood, J.P., Gilbey, S.G., Stoker, J.B. \& Mary, D.A.S.G. 2001. Water ingestion increases sympathetic vasoconstrictor discharge in normal human subjects. Clin Sci 100, 335-342.

Stauss, H.M. 2003. Heart rate variability. Am J Physiol 285, R927-R931.

Stern, M.D. 1975. In vivo evaluation of microcirculation by coherent light scattering. Nature 254, 56-58.

Story, G.M., Peier, A.M., Reeve, A.J., Eid, S.R., Mosbacher, J., Hricik, T.R., Earley, T.J., Hergarden, A.C., Andersson, D.A., Hwang, S.W., McIntyre, P., Jegla, T., Bevan, S. \& Patapoutian, A. 2003. ANKTM1, a TRP-like channel expressed in nociceptive neurons, is activated by cold temperatures. Cell 112, 819-829.

Strotmann, R., Harteneck, C., Nunnenmacher, K., Schultz, G. \& Plant, T.D. 2000. OTRPC4, a nonselective cation channel that confers sensitivity to extracellular osmolarity. Nat Cell Biol 2, 695-702.

Van Vliet, B.N. \& Montani, J.P. 1999. Baroreflex stabilization of the double product. Am J Physiol 277, H1679H1689.

Villanova, N., Azpiroz, F. \& Malagelada, J.R. 1997. Perception and gut reflexes induced by stimulation of gastrointestinal thermoreceptors in humans. J Physiol 502, 215-222.

Watanabe, H., Vriens, J., Suh, S.H., Benham, C.D., Droogmans, G. \& Nilius, B. 2002. Heat-evoked activation of TRPV4 channels in a HEK293 cell expression system and in native mouse aorta endothelial cells. J Biol Chem 277, 47044-47051.

Weir, J.B. 1949. New methods for calculating metabolic rate with special reference to protein metabolism. J Physiol 109, 1-9.

Zhang, L., Jones, S., Brody, K., Costa, M. \& Brookes, S.J.H. 2004. Thermosensitive transient receptor potential channels in vagal afferent neurons of the mouse. Am J Physiol 286, G983-G991. 